\title{
Reinventando Centroamérica. La construcción del imaginario social a partir de la novela de ficción ${ }^{1}$
}

María del Pilar López Martínez²

Universidad Autónoma de México, México

resumen

El estudio analiza el papel que la novela de ficción tiene en la constitución de imaginarios sociales en y sobre El Salvador y Guatemala, a partir de las novelas escritas después de los acuerdos de paz en Centroamérica. Apunta a la necesidad de profundizar en las investigaciones interdisciplinarias que vinculan esa generación de imaginarios con la producción, distribución y consumo de novelas y las nuevas temáticas y búsquedas estéticas de las obras literarias, con frecuencia determinadas por el mercado.

\begin{abstract}
This study addresses the role which fiction novels have in the formation of social imaginaries in and about El Salvador and Guatemala, based on the novels written after the peace agreements in Central America. It discusses the need to go into greater depth in interdisciplinary research linking that generation of imaginaries with the production, distribution and consumption of novels and the new themes and esthetic searches in literary works, as often determined by the market.
\end{abstract}

Palabras clave: literatura centroamericana, novela salvadoreña, novela guatemalteca, imaginario social

Keywords: Central American literature, Salvadoran novel, Guatemalan novel, social imaginary

1 Ponencia presentada en el XX Congreso Internacional de Literatura Centroamericana (ciLca) 2012. Recibido: 30 de marzo de 2011; aceptado: 12 de junio de 2011

2 Correo electrónico: pilarlmz@gmail.com

$$
L_{\text {etras }} 49 \text { (2011), ISSN 1409-424X }
$$




\section{Presentación}

Pasados los conflictos armados centroamericanos, resurge la novela de ficción. Tras años de haber sido relegada, la práctica escritural de ficción irrumpe en los terrenos otrora ocupados por la novela testimonio, principalmente. Sus motivos y técnicas son múltiples: la novela de ficción histórica, la novela de temas subjetivos, la novela social con tintes policíacos y de narcotráfico, entre otras. Lo cierto es que las novelas de ficción centroamericanas de los últimos diez años dibujan un trasfondo social y político, subjetivo o intimista en el que, considero, es posible leer la reinvención de Centroamérica.

Llamo reinvención al imaginario social que se construye desde la literatura al considerar que se trata sobre todo de un hecho cultural; es decir, está inmersa en la manifestación de las estructuras mentales de cierto grupo humano conformadas por conocimientos científicos, tradicionales, empíricos, así como por valoraciones éticas y estéticas del mundo.

La literatura forma parte de la cultura en una doble relación: la que se establece a través del lenguaje, como constructora de significado y sentido en la realidad, y la que se establece desde la dinámica social existente en el marco de las relaciones que producen a esta literatura y con ella sus características y especificidades. Una doble relación que se expresa en el sistema específico de signos que se generan desde el arte literario y los cuales transforman o establecen, reafirman, idealizan, cuestionan, subvierten o transgreden valores considerados otrora inmutables en las sociedades. Esas dos dimensiones, la de los acontecimientos inventados por el autor que dependen en gran medida de la gramática del relato- y la de la historia - sucesión de acontecimientos pertenecientes a la memoria colectiva - se trenzan y se apoyan para generar sentidos y múltiples posibilidades de lectura. Hoy es posible afirmar que gran parte del imaginario sobre Latinoamérica que sigue prevaleciendo entre la población mundial, se generó en la segunda mitad del siglo pasado 
gracias a novelas de autores que por su impacto y difusión en el continente, tuvieron un papel fundamental tanto en la construcción de la imagen como en la comprensión de las realidades regionales.

\section{Algunos elementos literarios}

La producción novelística de ficción El Salvador y Guatemala en los últimos diez años se ocupa de múltiples temas y genera diversos tópicos literarios. Luego de la novela testimonial, se comenzó a hablar de la literatura de posguerra, de la violencia o del cinismo, incluyendo en ella a novelistas como Horacio Castellanos Moya o Gerardo Guinéa Díez, por poner un ejemplo. Novelas en las que según Beatriz Cortez: «se pinta un retrato de las sociedades centroamericanas en caos, inmersas en la violencia de la corrupción» ${ }^{3}$. También se inició la publicación de la novela histórica o novela centroamericana contemporánea, en que los temas históricos son motivo para indagar y cuestionar las versiones oficiales de la historia, y en las que, explícita o implícitamente, se establecen posiciones sobre la relación entre el discurso histórico y el de ficción.

De la misma forma, surgieron novelas de ficción en las que se privilegia lo subjetivo, la historia individual. En ellas el deseo, la pasión, la sexualidad, son las temáticas que se abordan y en las que se propone ya no poner sobre la mesa las normas, los roles, la moral existente y cuestionarla, sino trasgredir cualquier posible intento de reordenamiento en cuanto a los roles sexuales. Jacinta Escudos o Sergio Mendizábal son un ejemplo.

Otras novelas abordan el tema de la memoria; de la memoria inmediata relacionada con la guerra vivida. Gerardo Guinea Diez o Manlio Argueta son escritores que han tocado el tema. En ellos la

3 Beatriz Cortez, «Estética del cinismo: la ficción centroamericana de posguerra». Ponencia presentada por la autora en el V Congreso Centroamericano de Historia., San Salvador, julio 2000, <www.ues.edu.sv/congreso/Cortez,\%20literatura.pdf>. Puede consultarse también: Beatriz Cortez, «La ficción salvadoreña de fin de siglo: un espacio de reflexión sobre la realidad nacional», Revista Cultura 85 (1999): 65-83. 
ficción es un instrumento de recreación para la imposible aprehensión de una realidad inexistente ya, pero permanente. Otro ámbito de la novela de ficción son los llamados Thriller, o novelas policíacas o sobre narcotráfico, ahí están las novelas de Rafael Menjívar. Los anteriores son sólo ejemplos de las temáticas abordadas por la escritura de ficción en los dos países.

Hasta hoy existen algunos ejemplos de crítica literaria que intentan abarcar la novela de ficción centroamericana sobre todo para el período que va de los años noventas a 2000. Estos se ocupan sólo de alguno de los tópicos mencionados anteriormente y por lo general se centran en alguno de los dos países.

Un esfuerzo importante, quizá menos analítico y más extenso, es el de Mauricio Aguilar Ciciliano, quien hace una revisión completa de los rasgos comunes y tópicos de la novela salvadoreña de la posguerra (1992-2000). El estudio plantea la indisoluble relación, dado el conflicto armado y las condiciones en que se vive en El Salvador de los años de ajuste estructural, de la ficción novelesca y la realidad del país. Su análisis recorre 42 novelas encontradas en esos años.

Otro esfuerzo de elaboración de corpus literario es el caso de Ronald Flores en Signos de fuego, que recorre la narrativa guatemalteca desde 1960 hasta 2000. En el se afirma en la existencia de una tendencia predominante de la literatura guatemalteca de finales del siglo xx, cuyo principal signo es el haber sido gestada en condiciones adversas, motivada por la resistencia y la creatividad como alternativa ante la represión y la guerra.

También podemos encontrar textos de Arturo Arias sobre Guatemala, quien en el estudio de algunas obras de la llamada novela de posguerra, resalta la importancia de la literatura en la continuidad de la lucha contra las estructuras de poder y la dominación en el continente. Por su parte, Beatriz Cortez define como la estética del cinismo, la novela surgida de la guerra en El Salvador. Una estética cuyo centro es la violencia y el caos que se vive en las urbes centroamericanas actuales. En ella, la construcción de una subjetividad 
subalterna a priori, al no representar ninguna alternativa a la utopía revolucionaria, llevará al suicidio al sujeto literario que se enuncia.

Estos estudios se han ocupado fundamentalmente de la llamada literatura de posguerra; es decir, de la producción literaria durante el primer decenio de paz (1992-2002) y de los referentes y las temáticas ligadas al desencanto, la violencia, los motivos «oscuros del sujeto». Las novelas más conocidas — por su impresión y difusión en Europa y el continente americano- han sido aquellas que abordan la realidad centroamericana de fines del siglo pasado como sumergida en una espiral de violencia y al fenómeno literario desde, por un lado, la visión del contra discurso y la resistencia, y por el otro, la falta de alternativas y el cinismo con que se mira la realidad actual.

Transversales a estas discusiones, se encuentran las que establecen paralelismos entre la literatura y los procesos regionales en el sentido de que, habiendo vivido procesos similares de despojo, colonialismo, resistencia, revoluciones, los países del istmo conforman una región literaria. Estas mismas discusiones, abonarán en la construcción de una caracterización de la región geográfica, apoyada de la producción y distribución de obras con temas específicos.

Pero ¿cómo participa esta narrativa en la construcción del imaginario social? En los estudios existentes sobre la relación del hombre con el mundo, el llamado imaginario social ha sido largamente tratado como categoría de conocimiento. Retomo la reflexión de Peter Berger y Niklas Luckman ${ }^{4}$ según la cual la realidad, como realidad socialmente aceptada como evidente, no es más que una objetivación de significado legitimado por universos simbólicos que le dan coherencia. Dichos universos, no exentos de presión derivada de la lógica cultural que los construye (tal como lo demostraría Lukacs) ${ }^{5}$ se constituyen y reconfiguran, suplantando, ocultando o generando significados diversos.

4 Peter Berger y Thomas Luckman, La construcción social de la realidad (Buenos Aires: Amorrortu, 1986).
5 Georg Lukács, Historia y conciencia de clase (Barcelona: Grijalbo, 1976). 
Como objeto de estudio, el imaginario social sólo puede ser analizado desde el momento en que se objetiviza; es decir, a partir de que es representado. Su representación más evidente se encontrará dentro del universo discursivo y en tanto representación, estará inscrita en la semiótica. El orden narrativo estructurará, es decir, integrará, hará inteligibles sus elementos y sobre todo, dotará de sentido a ese imaginario permitiéndonos así conocerlo. Los elementos que conforman los imaginarios sociales se relacionan con la historia y la cultura de los pueblos en el sentido más amplio posible: desde los mitos y los arquetipos, hasta el orden normativo y el valor otorgado a ciertos saberes.

Los universos diegéticos construidos por las novelas de ficción del periodo propuesto, participan de la deconstrucción de saberes y generan la emergencia de valores olvidados. Las novelas forman parte de la reinvención de un imaginario social sobre la región, cuando de inicio plantean la posibilidad de que aquello que ha sido dado como un hecho definitivo (el orden establecido, el valor que se le otorga a ciertos comportamientos, la división tajante entre lo público y lo privado, entre otros) no es más que parte de una historia contada entre muchas existentes, la mayoría de las cuales han estado latentes pero reprimidas.

En el proceso de imbricación de la literatura en la transformación del imaginario social sobre la región centroamericana, en particular sobre El Salvador y Guatemala, las novelas de ficción del último decenio han contribuido de manera significativa, ya que participan en la construcción del conocimiento y en la interpretación que se tiene sobre los procesos centroamericanos. Son novelas que, dados los autores - muchos de ellos viven en el exilio- y las características de producción — son de editoriales europeas- se distribuyen, se leen y se estudian entre lectores externos, más que en sus propios contextos. Esa lectura desde el exterior, la falta de conocimiento sobre las realidades centroamericanas de la mayoría de las sociedades y el papel que los medios de comunicación juegan en 
la construcción de opinión pública, abonan significativamente en la caracterización de ciertas sociedades.

De la misma manera, en los dos últimos decenios se ha dado un desplazamiento en las temáticas tratadas por las novelas de ficción. Si bien se continúa con la llamada literatura de posguerra, se inicia el tratamientos de temas más universales y menos regionales, como en las obras de Rodrigo rey Rosa, en los que los escenarios y referentes cambian. Sin embargo, es posible encontrar en ellas lo centroamericano como una identidad con características específicas. Un claro ejemplo de lo anterior es la novela Berlín años guanacos, del salvadoreño David Hernández, que se desarrolla conjuntamente en Berlín y en El Salvador durante los años de la guerra.

Como temáticas, además del la de género en la que se inicia la producción mucho más activa de novelas de ficción escritas por mujeres como la ya mencionada Jacinta Escudos o Carol Zardetto, se inicia la producción de obras escritas por indígenas con tópicos propios, que si bien han tenido poca visibilidad, va cobrando fuerza.

\section{Elementos contextuales}

Un elemento fundamental en la producción y distribución de las obras literarias es la existencia de los medios. En Centroamérica, las editoriales públicas han estado vinculadas a las universidades estatales y, en algunos países, al Estado. La más prolífica ha sido Costa Rica, sin embargo, tanto en Guatemala como en El Salvador, debido a la guerra, las actividades de fomento editorial prácticamente desaparecieron. Hoy siguen funcionando en Guatemala la de la Universidad de San Carlos de Guatemala, y la Editorial Cultura, adscrita al Ministerio de Cultura; y en El Salvador la Editorial de la Universidad de El Salvador y la de la privada Universidad Centroamericana (UCA). Han surgido pequeñas editoriales privadas para apoyar la distribución, algunas de las cuales han mejorado ostensiblemente el tema de la distribución, F\&G Editores en Guatemala, que utiliza la red Internet para acceder a otros países, por ejemplo. 
Es necesario mencionar, sin embargo, que el tema de una política cultural y fomento editorial es fundamental en la región, a excepción de Costa Rica, y que a pesar de los esfuerzos, las editoriales trasnacionales ganan el mercado colocando las obras en librerías de todo el mundo (servicios de traducción, marketing, difusión en medios, presentaciones y viajes internacionales, etc ayudan en este sentido), mientras que las editoriales de la región no logran trascender las fronteras nacionales. Estas mismas editoriales trasnacionales, en muchos casos definen temas, de acuerdo al marketing existente, y con ello, abonan en la representación de las características que se difunden sobre la región.

Las dos grandes escuelas de estudios y crítica sobre la literatura centroamericana en América, la que se desarrolla en Costa Rica y la de Los Ángeles, tienen una difusión también local en gran medida, aunque es de agradecer que muchos de los materiales sean de acceso público en la red. Por otro lado, es importante mencionar, como en casi toda América Latina, el desconocimiento local sobre los propios autores y sobre la producción literaria, en particular la de las novelas de ficción.

Pareciera entonces que desde las metrópolis se siguen dictando las características y tópicos de la representación existente sobre Centroamérica, simplificando la imagen que se puede tener de una realidad compleja y en la que participan no sólo múltiples voces, sino múltiples realidades que emergen de procesos sociopolíticos y que reclaman tener su propia voz y cuyas preocupaciones son distintas o se abordan desde otros ángulos, de aquellos que mayoritariamente se difunden.

El fenómeno de la literatura en Centroamérica y su relación con la construcción de imaginarios sociales, concentra ciertas características que siguen los procesos globales en torno a la producción literaria actual: definición de políticas de producción, distribución y consumo de casas editoriales; definición de políticas culturales; y uso de las nuevas tecnologías en el quehacer literario, entre otros. 
Lo cierto es que a pesar o además de que conviene estudiar el fenómeno literario en su totalidad e integración con procesos más globales que interfieren en él, a lo interno, lejos de perder su sentido identitario, los elementos que confluyen en lo que denominamos literatura centroamericana siguen diferenciándola, poniendo sus voces en el fluir de la literatura universal. 